\title{
Narrar... para não esquecer
}

\author{
Rejane Vecchia da Rocha e Silva*
}

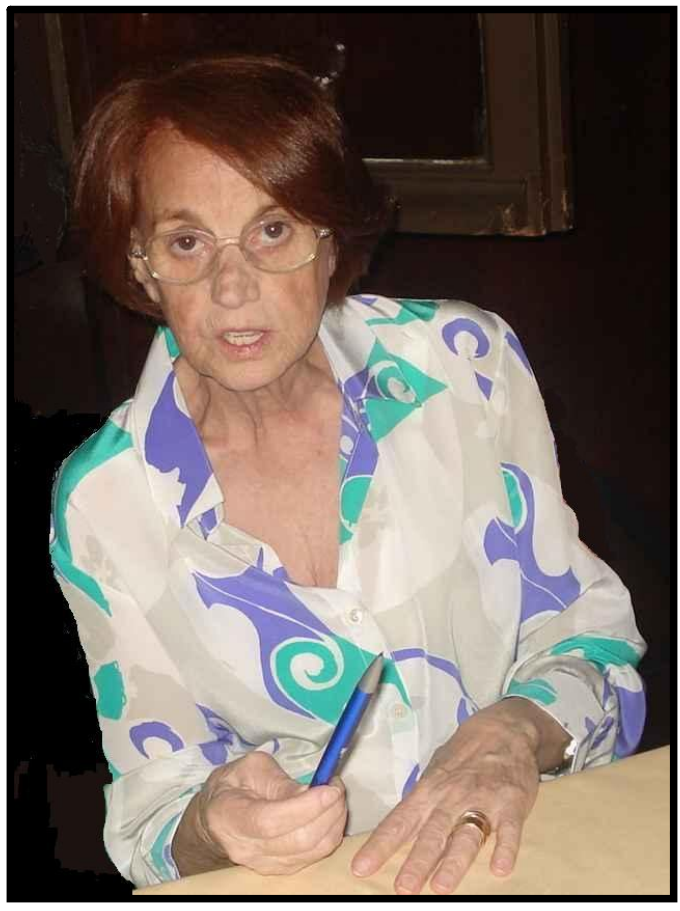

Maria Aparecida Campos Brando Santilli
A narrativa de uma vida faz parte de um conjunto de narrativas que se interligam, está incrustada nas histórias dos grupos a partir dos quais os indivíduos adquirem a sua identidade e por isso a memória individual, separada em absoluto da memória social é uma abstração quase destituida de sentido.

Paul Connerton

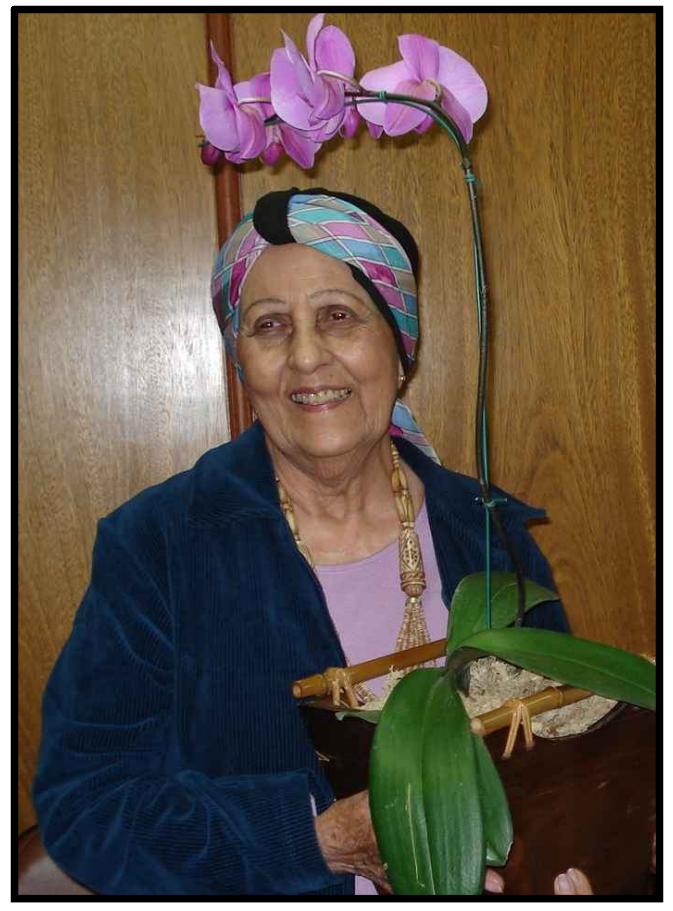

Benilde Justo Lacorte Caniato

A formação da Área de Estudos Comparados de Literaturas de Língua Portuguesa, da Universidade de São Paulo, constitui-se um exemplo significativo de experiências de vidas que ao aproximarem-se puderam estabelecer e confirmar, dentro das especificidades de seus objetos de pesquisa, de seus cursos ministrados e de todo o trabalho que envolve a vida acadêmica de um professor, o entrelaçamento de visões de mundo que compartilharam muitas vezes da relevância sempre presente dos estudos das literaturas de língua portuguesa, das comparações estabelecidas entre estas (além de outras cujas perspectivas históricas tornaram possiveis algumas das interlocuções propostas), das pesquisas voltadas para a produção literária dos países 
africanos de língua portuguesa ou pela sistemática e necessária comunhão entre a vida pessoal e a vida profissional que a seu modo foi também tecendo a memória particular de cada um. Entre vários nomes que compõem essa História lembramos hoje especialmente o de duas professoras, cujas contribuições foram fundamentais para a Área Benilde Justo Lacorte Caniato e Maria Aparecida Campos Brando Santilli - que há pouco nos deixaram.

A primeira delas, antes de se dedicar exclusivamente à Área, foi docente da disciplina Filologia e Língua Portuguesa, interessando-se sempre pelas questões da língua portuguesa no mundo. Em 1979 motivada pela disciplina Literaturas Africanas de Expressão Portuguesa ministrada pela Profa. Maria Aparecida Santilli que, então, cursou, inicia suas pesquisas em torno do repertório literário cabo-verdiano a partir do romance Hora de Bai de Manuel Ferreira (escritor português que entre 1941 e 1947 permaneceu no Arquipélago). As investigações da Profa. Benilde vão se organizando em torno de textos de escritores cabo-verdianos, poetas e prosadores, enfatizando o exame da língua literária do Arquipélago, como ela própria afirma em entrevista concedida à Revista Via Atlântica, $\mathrm{n}^{0}$ 10. Assim, fruto de uma incansável paixão pela literatura, a partir da qual se debruçou para o uso do português e do crioulo e cada vez mais seduzida pelos horizontes que vinham sistematicamente chegando do Arquipélago cabo-verdiano, publicou os seus "Percursos pela África e por Macau”, "A solidão de mulheres a sós”, as "Travessias Atlânticas - literatura nos países de língua portuguesa" para lembrarmos algumas de suas inquietações e o empenho com que tais preocupações foram transformadas em textos críticos e atentos às conformações de realidades que sempre insistem em navegar nas páginas da ficção, mesmo quando as turbulências políticas e econômicas de seus contextos históricos específicos parecem impeli-los para trás.

Seu trabalho, portanto, apresenta uma dimensão particular a respeito do universo que é o da literatura e seus modos sempre muito diversos de falar, assim como um olhar atento e dinâmico aos diferentes 
modos de ser e de estar no mundo, a começar por um querer partir/ficar que o romance Hora di Bai possibilitou.

O corpo que é escravo, vai;

O coração, que é livre, fica...

Corpo, qu' ê nego, as ta bai;

Coraçom, qu' ê fôrro, as ta fica...

Conciliando sempre as exigências acadêmicas e as de mãe exemplar, deixa-nos a lembrança viva dos caminhos abertos por um coração livre e generoso.

A segunda, Profa. Maria Aparecida Santilli, ingressou na disciplina de Literatura Portuguesa na década de 1960 e nos inícios da década de 70, participou como membro da direção do Centro de Documentação para a América Latina (CEDAL), da USP. Foi sob sua responsabilidade e empenho que se deu a abertura de uma nova área de estudos, a de Literaturas Africanas de Língua Portuguesa, no Departamento de Letras Clássicas e Vernáculas da FFLCH. Caberia aqui retomar o texto introdutório do livro "Africanidade":

As Literaturas Africanas de Língua Portuguesa já se alastraram entre nós.

As páginas deste livro - "Africanidade" - serão, pelo menos, um documento de seu interesse e fascínio a ultrapassarem o Atlântico. De lá para cá, essa outra mão do trânsito literário que se desejava, consuma a pista-dupla para um pleno intercâmbio de culturas, oxalá saudável, superando restrições que o passado estabeleceu.

Com as literárias, mais fundações se firmarão: de relacionamentos humanos, sociais. Ou outros.

E darão uma História, a História-Nova entre culturas umbelicalmente afins que começa a escrever-se.

Vale, ainda, lembrar que na década de 70, a Universidade enfrenta um momento profundamente dramático e violento assim como toda a sociedade brasileira, sobre-vivendo à ditadura militar. Desse modo, sugerir novas frentes de pesquisa a partir de literaturas que trazem em suas páginas a contestação viva contra as formas de opressão estabelecidas pelos regimes ditatoriais e coloniais não só se 
constitui numa atitude pioneira mas sobretudo de confronto relativamente a um "status quo" que exigia, soberanamente, o silenciamento.

Necessário era (e é) então ver-se a Universidade não só como o espaço para o debate intelectual mas também para a discussão das condições materiais da vida da sociedade brasileira, especialmente em seus compromissos e responsabilidades com a comunidade. Tal entendimento norteou sempre as ações da professora e da cidadã Maria Aparecida Santilli. A defesa da abertura de espaços que conduzissem o país em direção às possibilidades de sua, de fato, democratização, tornou-se a tônica de sua vida. Resultados de suas preocupações, os leitores hoje podem contar com "Arte e representação da realidade no romance português contemporâneo", "Africanidade”, "Estórias africanas - História e Antologia", "Paralelas e tangentes - entre literaturas de língua portuguesa”. Para além disso, não podemos deixar de vê-la como um dos pilares da Área de Estudos Comparados de Literaturas de Língua Portuguesa, sempre em construção.

Professoras Benilde e Cida,

Como afirma Sigmund Bauman,

... aqueles que embarcam numa vida de conversação com a experiência humana deveriam abandonar todos os sonhos de um fim tranqüilo de viagem. Essa viagem não tem um final feliz toda a sua felicidade se encontra na própria jornada.

\footnotetext{
* Profa. Dra. de Literaturas Africanas de Língua Portuguesa da Universidade de São Paulo (USP).
} 